\title{
Intermediate Osteotomy and other Unique Techniques used in Reduction Rhinoplasty
}

\author{
${ }^{1}$ Niveditha J Sagar, ${ }^{2}$ Chidananda R Devasamudra
}

\begin{abstract}
Background: A 25-year-old male patient came with a history of nasal obstruction on the left side. He was also concerned about his nasal framework deformities, such as gross deviation of the nose to left, hump over the nose, asymmetrical nostril, and overall bulky nose.
\end{abstract}

Materials and methods: Detailed history was taken and examination done to rule out contraindication to septorhinoplasty. Expectations, requirements, and postoperative results of the patient were understood. Open approach reduction rhinoplasty was carried out. Unique techniques, such as intermediate and transverse osteotomies were done to achieve the required results.

Results: Bulky deviated nose was reduced to an esthetically good-looking nose by humpectomy, four types of osteotomies, extended spreader grafts, columellar strut, and Tipplasty.

Conclusion: Surgical steps must be undertaken in order to achieve good esthetic results. Surgeries, such as humpectomy must be done before osteotomies, intermediate osteotomies must be done before lateral osteotomies, and Tipplasty must be done after osteotomies.

Keywords: Intermediate osteotomy, Medial lateral, Reduction rhinoplasty.

How to cite this article: Sagar NJ, Devasamudra CR. Intermediate Osteotomy and other Unique Techniques used in Reduction Rhinoplasty. Clin Rhinol An Int J 2016;9(1):6-12.

Source of support: Nil

Conflict of interest: None

\section{INTRODUCTION}

The bony nasal vault represents a complex threedimensional (3D) structure. With a widely divergent spectrum of nasal bony deformities, use of a single technique will often result in inconsistent results.

\footnotetext{
${ }^{1}$ Assistant Professor, ${ }^{2}$ Senior Consultant

${ }^{1}$ Department of ENT-HN, DM-Wims Medical College and Research Center, Meppadi, Kerala, India

${ }^{2}$ Department of ENT-Facial Plastic, RMV Hospital, Bengaluru Karnataka, India

Corresponding Authors: Niveditha J Sagar, Assistant Professor, Department of ENT-HN, DM-Wims Medical College and Research Center, Meppadi, Kerala, India, Phone: +918971491130, e-mail: niveditha150@gmail.com

Chidananda R Devasamudra, Senior Consultant, Department of ENT-Facial Plastic, RMV Hospital Bengaluru, Karnataka, India Phone: +918971611749, e-mail: devasamudra@gmail.com
}

In India, reduction rhinoplasty ${ }^{1,2}$ is the most common esthetic procedure done on the nose, because the nose is the most vulnerable organ to be injured during domestic violence, sports injuries, or in road traffic accidents. Nasal bone fracture, deviation and deformity of the nose, and nasal obstruction are common problems following trauma to the nose. If the deviation and deformities are not corrected immediately, the patient will land up with conditions, such as a crooked nose or a slanted nose with or without functional problems. In addition, Indians are unique in their thickness, color, texture, and skin tone. Indians have a broad dorsum, broad alar base, thick skin, bulbous tip, and a prominent hump over the dorsum. Esthetics of Indian nose is a mixture both Caucasian and Asian races.

\section{CASE REPORT}

A 25-year-old male patient came with a history of nasal obstruction on the left side, since 2 years. He was also concerned about his nasal framework deformities, such as gross deviation of the nose to left, hump over the nose, asymmetrical nostril, and overall bulky nose (Fig. 1).

We spent time with the patient to know the detailed history, general condition, and expectations. Another advantage of spending time with the patient is to understand his psychological, economic, and social status. He is a young software professional with high expectations, anticipating good results after the surgery.

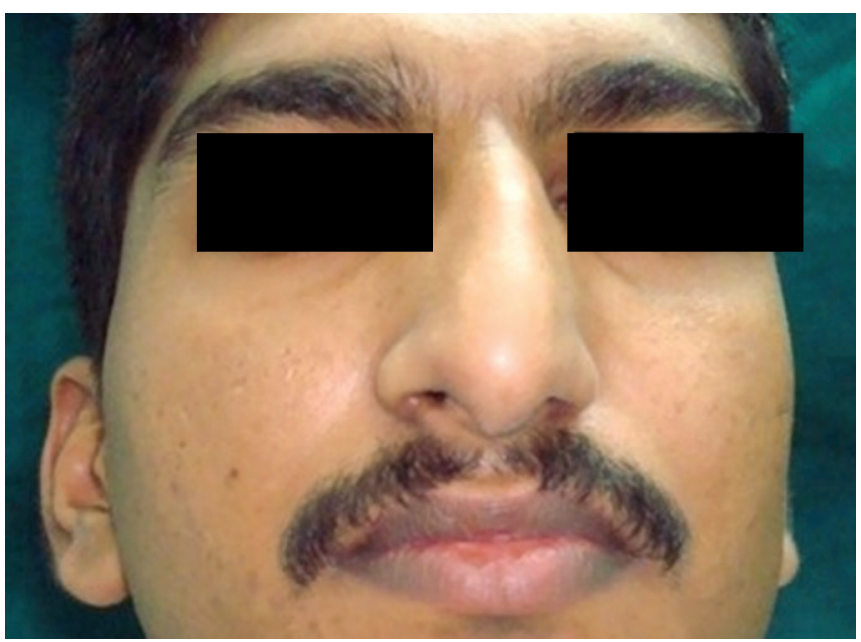

Fig. 1: Bulky nose with hump over the dorsum, tip drooping, and asymmetrical nostril 
History taking in this case was patient centric. The patient was worried about both external appearance of the nose and nasal obstruction. History of trauma and previous surgeries were ruled out. No history suggestive of sinusitis, systemic diseases, such as epilepsy or asthma was present. Patient's requirements and expectations were carefully noted. By knowing the expectations of the patient you can rule out body dysmorphic disorder and failures after surgery.

On examination of the nose, it was found that the external nose was bulky to the patient's face, there was gross deviation of the nasal framework to the left, with a bony cartilaginous hump over the dorsum, tip drooping, and asymmetrical nostril. On anterior rhinoscopy, we observed caudal dislocation of the septum to the right, gross deviation of the cartilaginous septum to the right, and bony spur on the left side. Nasal valve angle was compromised on the left side. There were no signs suggestive of paranasal sinusitis. General and systemic examination was done to rule out other diseases.

Routine and special investigations were done to know the general condition of the patient and to rule out contraindications for rhinoplasty. Before posting the patient for rhinoplasty, written valid consent was taken for the surgery. The patient was informed about the steps of the surgery as well as preoperative and postoperative precautions. We must understand the patient expectations, requirements, and explain the possible alterations in the nasal framework. While discussing the postoperative results, try to identify body dysmorphic disorder and unrealistic expectations.

\section{Surgical Procedure}

Clear instructions were given to the anesthetist to use oral South Pole ring Adair Ellwyn endotracheal tube

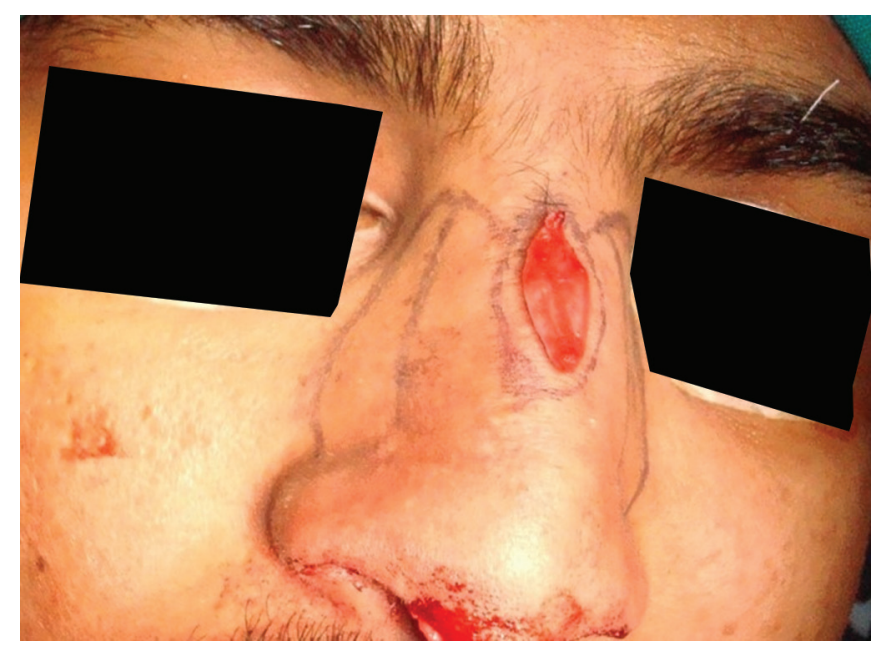

Fig. 3: After resection of bony cartilaginous hump for intubation. The intubation should not alter the shape of the nose and tube must be in the midline. Eyes are protected by applying lubricating eye ointment and cover the eyes with 1 inch JMS Meditape ${ }^{\circledR}$. Face and neck were draped till the clavicles were done with betadine. Local anesthesia solution ( $1 \%$ xylocaine with 1 in 100,000) was injected to the nasal framework and nasal septum by using 26 G 1 1/2 inch needle.

Open-approach septorhinoplasty was planned. A superficial musculoaponeurotic system flap was elevated over the nasal framework till the nasion. A bony cartilaginous hump was identified. The skin flap was repositioned over the nasal framework and marking done over the hump to be removed (Fig. 2). The hump was resected with the no.15 blade (cartilaginous part) and Rubin's humpectomy osteotome (bony part) (Fig. 3). By doing humpectomy, we created open roof deformity. To close the open roof deformity and to reduce the width of the nasal dorsum, medial, intermediate, and lateral osteotomies were done (Fig. 4).

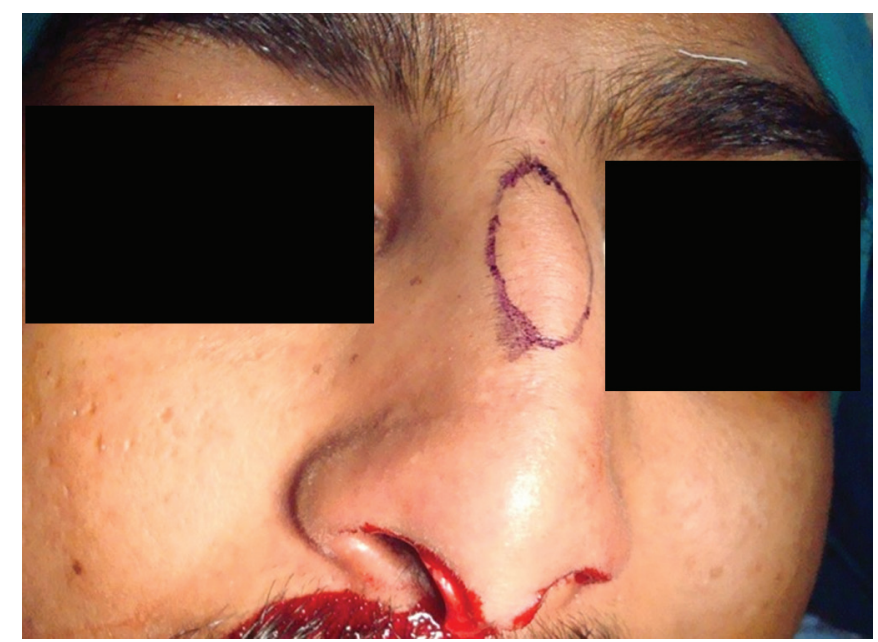

Fig. 2: Humpectomy marking on the skin of the nasal dorsum

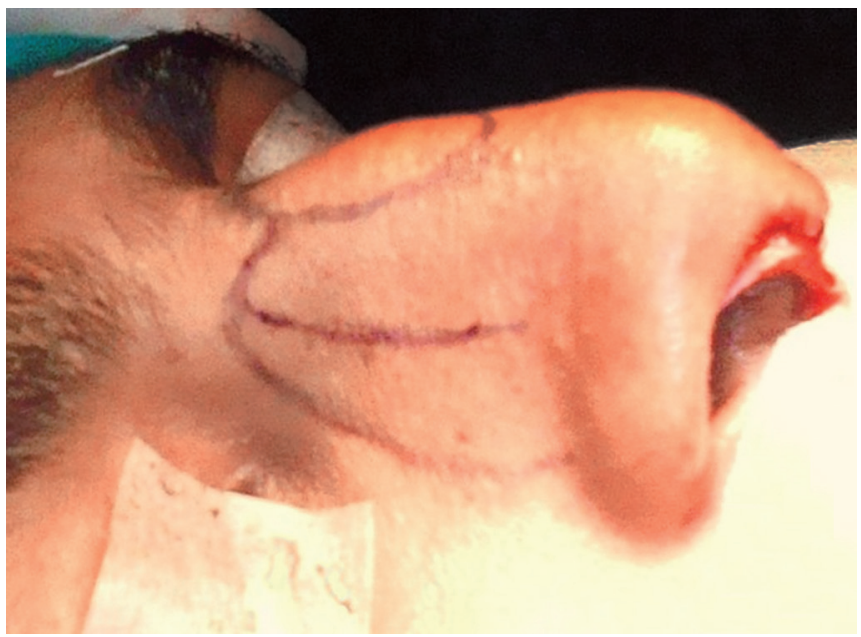

Fig. 4: Skin marking for medial, intermediate, and lateral osteotomies 
Before the osteotomies, the septal deviation was corrected and septal cartilage harvested (Fig. 5). The same septal cartilage can be used for extended spreader graft (ESG), columellar strut (CS), and cap grafts (Fig. 6). Nasal cavities are packed with ribbon gauge to avoid collection of the blood in the nasopharynx after osteotomies and it also helps in applying pressure on the fractured bony nasal wall.

Medial osteotomies ${ }^{3}$ were done on both the sides as an initial step to close the open roof deformity. Intermediate osteotomies must be done before going for lateral osteotomies. Lateral osteotomies ${ }^{4-6}$ are done after intermediate osteotomies $^{7,8}$ to narrow the width of the nasal dorsum. The bony framework was still deviated to the left even after medial, intermediate, and lateral osteotomies. So, we planned a transverse osteotomy on the left side. Marking was done over the skin as shown in picture (Fig. 7). We have to connect the fracture lines of both the medial osteotomies. We can do transverse osteotomy with the help of a lateral osteotome. Here, in this case, we have used left lateral

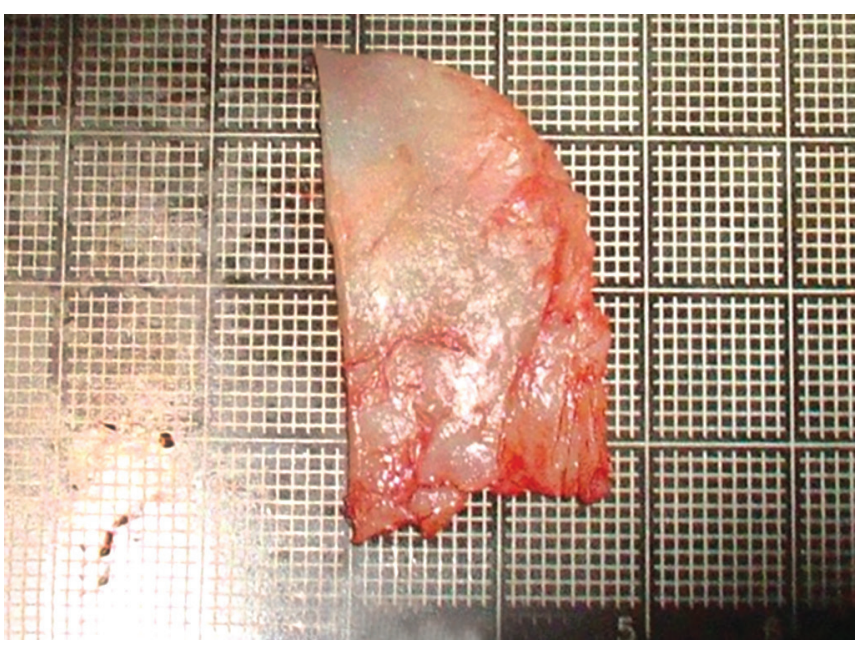

Fig. 5: Harvested septal cartilage

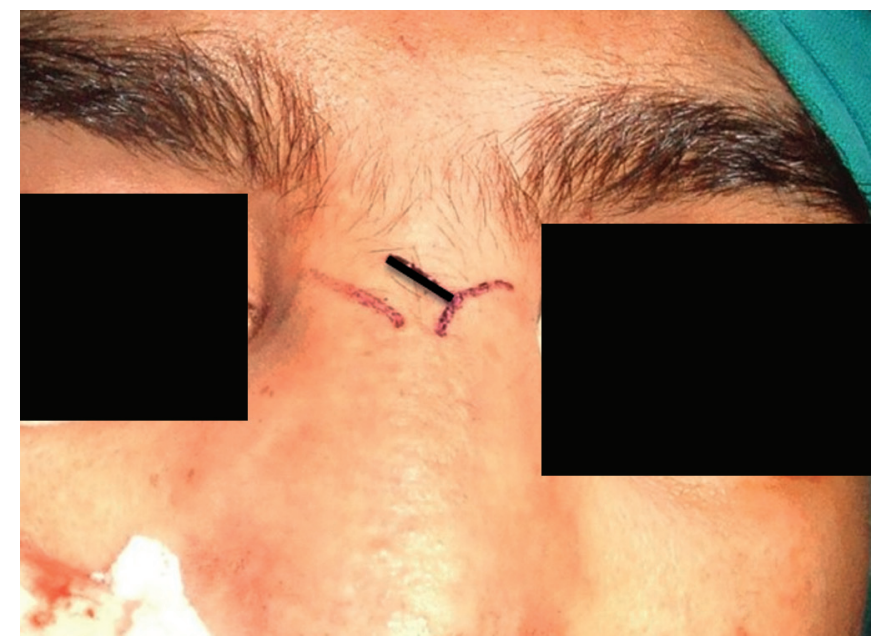

Fig. 7: Transverse osteotomy marking (black color line showing the osteotomy line) osteotome. After transverse osteotomy, ${ }^{9}$ we fractured the nasal framework by applying pressure on the left side to move the bony framework to the midline (Fig. 8). Pressure was applied on the fractured nasal framework for 5 to 8 minutes (along the fractured line of osteotomies, with the thumb and index finger to avoid primary bleeding, postoperative ecchymosis, and periorbital edema).

Extended spreader graft ${ }^{10,11}$ was kept on both the sides of the dorsal strut and sutured on both the sides, sandwiching the septum to increase the nasal valve angle ${ }^{12}$ and to get a straight nasal dorsum. Columellar strut was sutured to the anterior nasal spine below and spreader graft above to reconstruct the septum and to create an "L" strut. This provided support to the tip (Fig. 9).

Cephalic resection of the lower lateral cartilage was done on both the sides to reduce the bulk of the tissue in the supratip area and to create an alar groove. Care must be taken not weaken the alar cartilage by overresection. We must leave at least $5 \mathrm{~mm}$ caudal alar cartilage connected

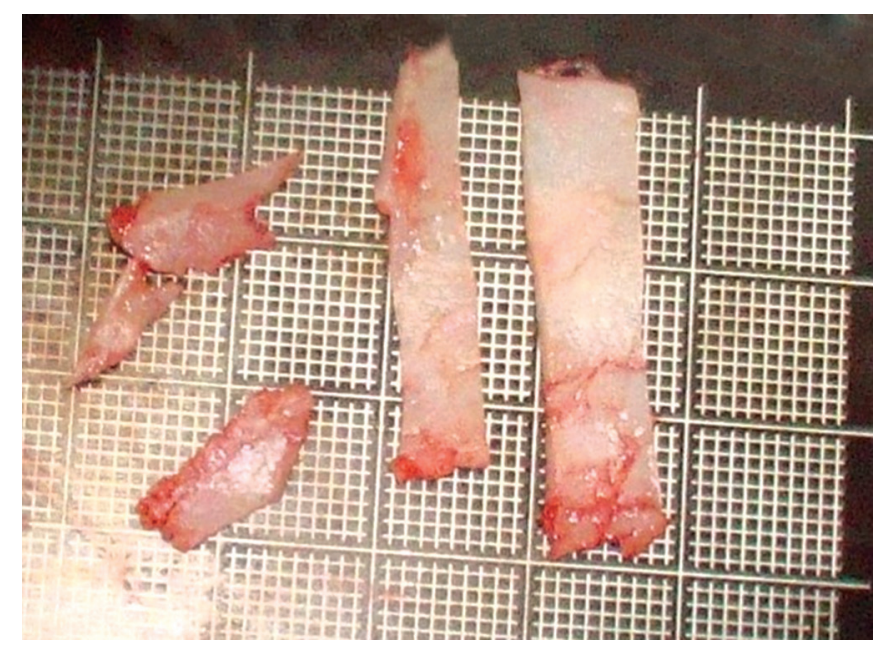

Fig. 6: Harvested septal cartilage can be used as extended spreader graft, columellar strut, and cap graft

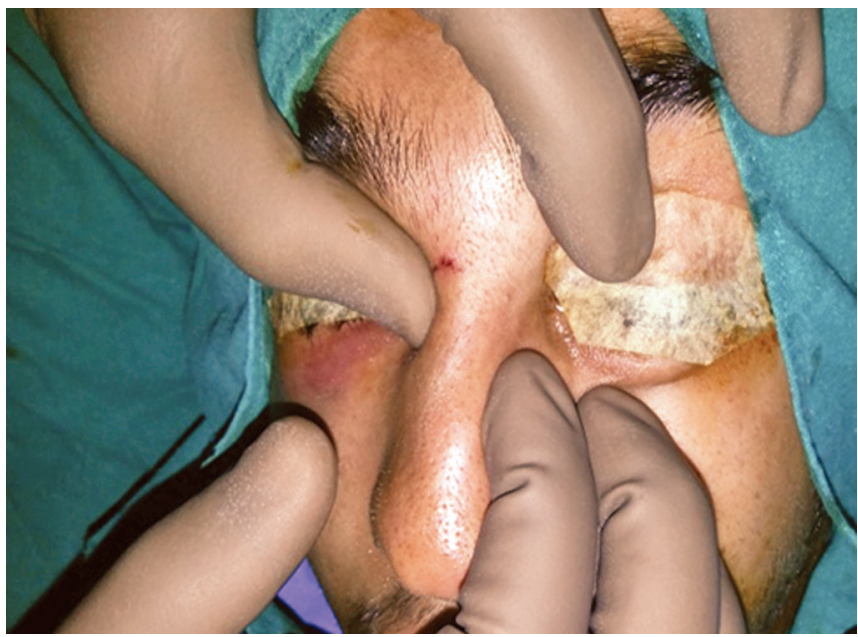

Fig. 8: Applying digital pressure over the nasal framework to get a straight dorsum 


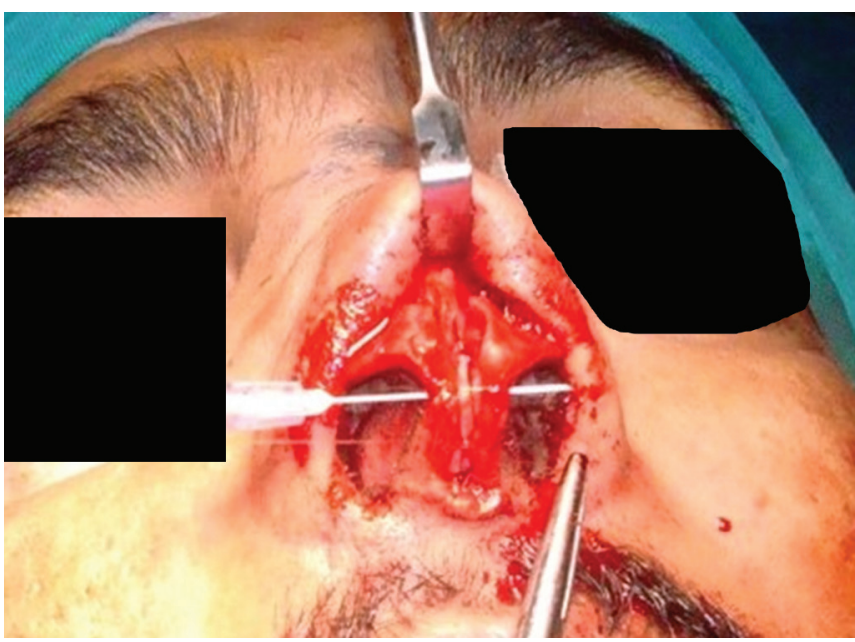

Fig. 9: Columellar strut sutured to the anterior nasal spine inferiorly

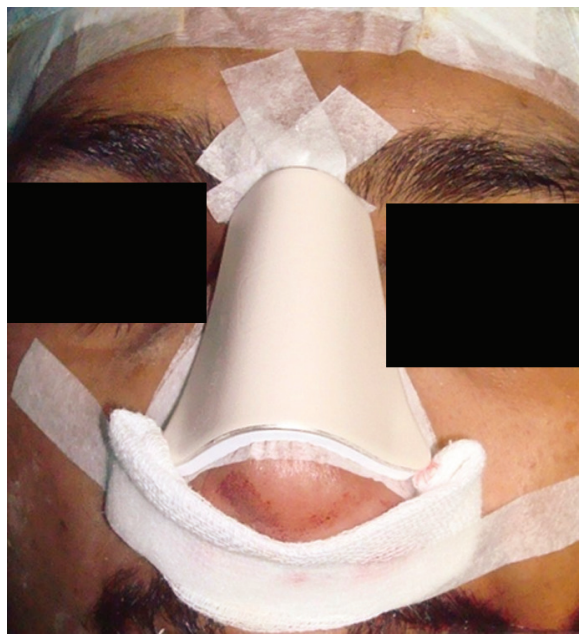

Fig. 11: Dressing done after the suturing, nasal packing, internal splint, and external splint application

to the dome and columella. Interdomal suturing was done and columellar suturing done to stabilize and sharpen the tip. Excessive projected cartilages (after tip suturing and tip reconstruction) were trimmed off to get a smooth surface over the nose. Skin flap was repositioned to see the tip projection and nasal dorsum. We have achieved required results, so final suturing was done.

Internal nasal splint was kept inside the nasal cavities and sutured sandwiching the reconstructed nasal septum. These splints will support the reconstructed nasal septum and prevent adhesions between septum and turbinates. It also helps in cleaning the nasal cavity postoperatively. Splints are properly positioned inside the nasal cavity to avoid pressure sores in the nostril. Anterior nasal packing is done using a $10 \mathrm{~cm}$ merocel. Merocel was smeared with Softamycin ointment before inserting into the nasal cavity, followed by soaking of the merocel pack with betadine.

Tincture iodine solution was painted over and around the nose. It will help the glove paper and JMS Meditape to stick better to the skin. The glove paper is cut according

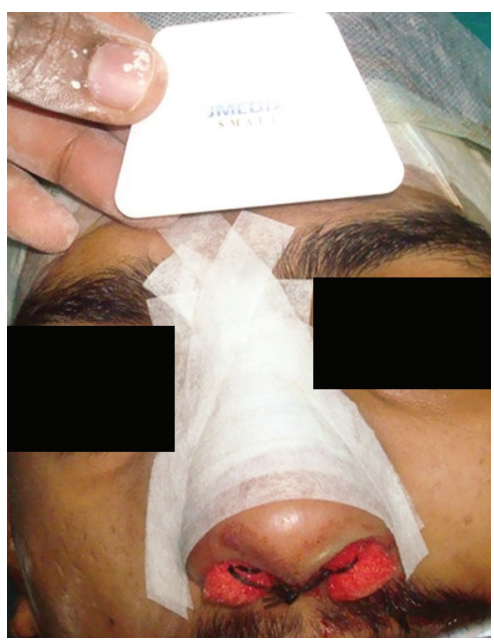

Fig. 10: A half inch plaster is stickled over the nose

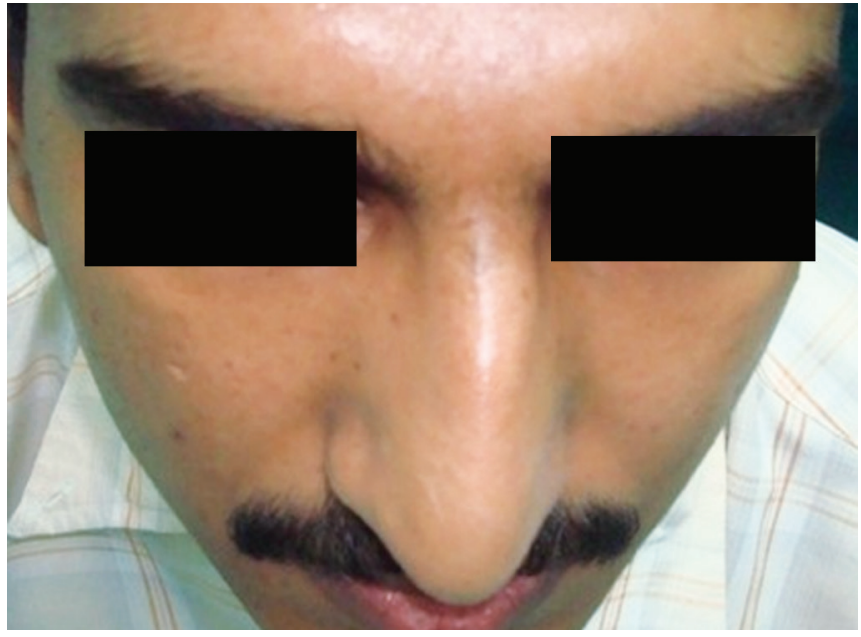

Fig. 12: Aerial view before surgery

to the size of the nose and made wet. Place it over the nose. A half-inch plaster is applied over the glove paper as shown in picture (Fig. 10). External aluminum nasal splint (Xomed Medtronic's ${ }^{\mathrm{TM}}$ ) was used to keep the aligned bony cartilaginous nasal framework in the midline and desired position. The external splint edges (all 4 corners) are slightly everted to avoid pressure necrosis of skin. Slowly the splint is bent medially so that it will press and align the reconstructed nasal framework. NeosporinH Ointment was applied over the sutured surgical wound. Gauge piece is kept and dressing done over the columella (Fig. 11).

Photographs showing the results of the unique techniques: Used in reduction rhinoplasty (Figs 12 to 19).

\section{Chronological Order of Surgical Steps in Reduction Rhinoplasty}

Reduction rhinoplasty included the following steps: Skin flap elevation, humpectomy, septal cartilage harvesting and septoplasty, rasping the sharp edges of the bone, medial 


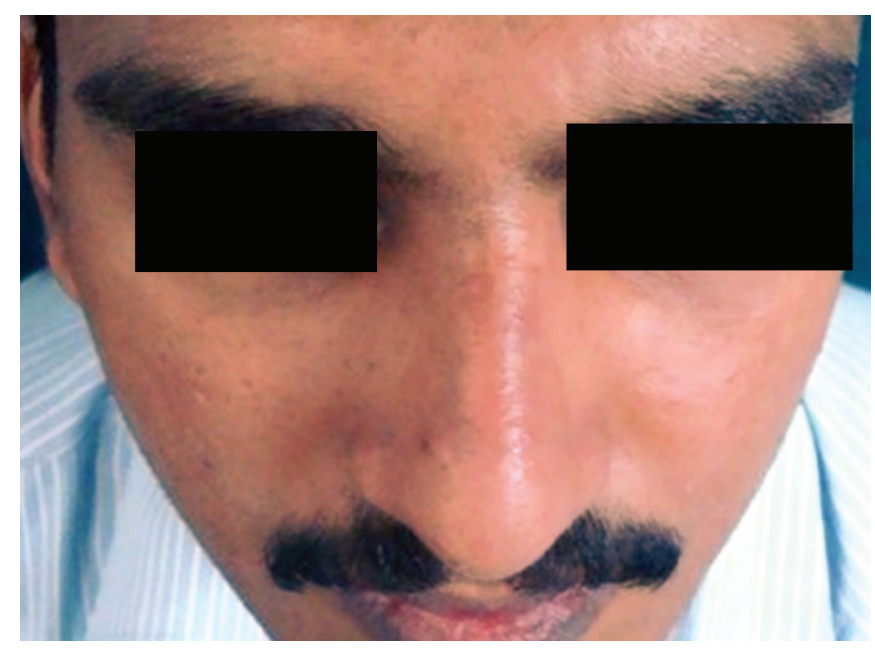

Fig. 13: Aerial view after surgery

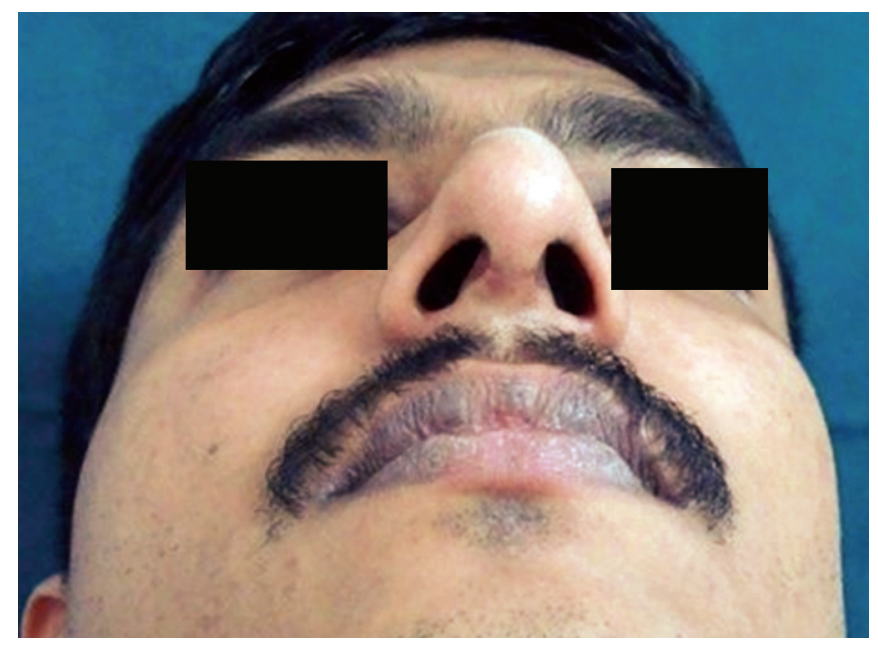

Fig. 15: Basal view after surgery

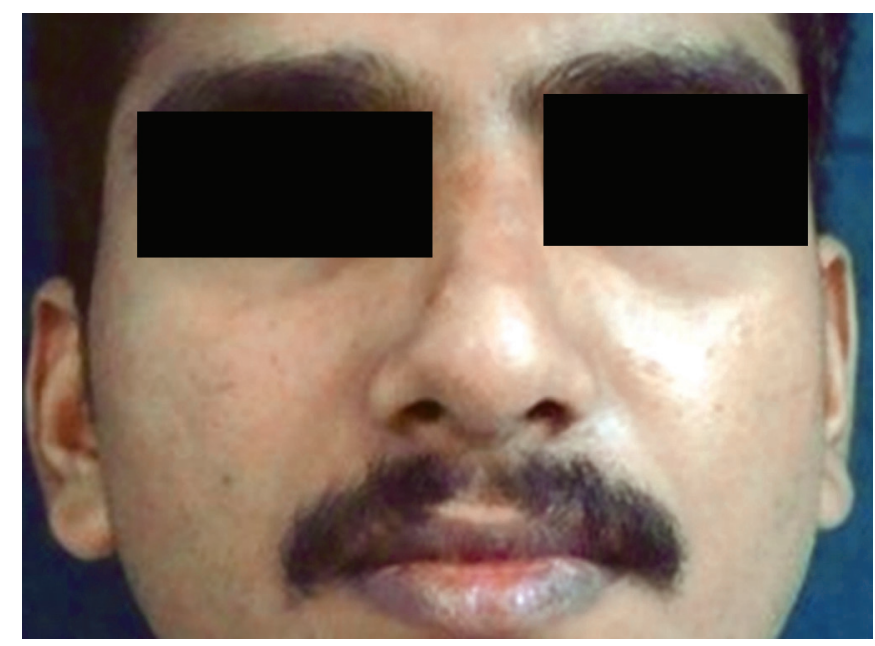

Fig. 17: Profile view after surgery

osteotomies, intermediate osteotomies, lateral osteotomies, transverse osteotomies, ESG suturing, CS suturing, cephalic resection of lower lateral cartilage, interdomal suturing, Tipplasty with or without cap graft, surgical wound suturing, internal nasal splint suturing, anterior nasal packing, dressing with external nasal aluminum splint.

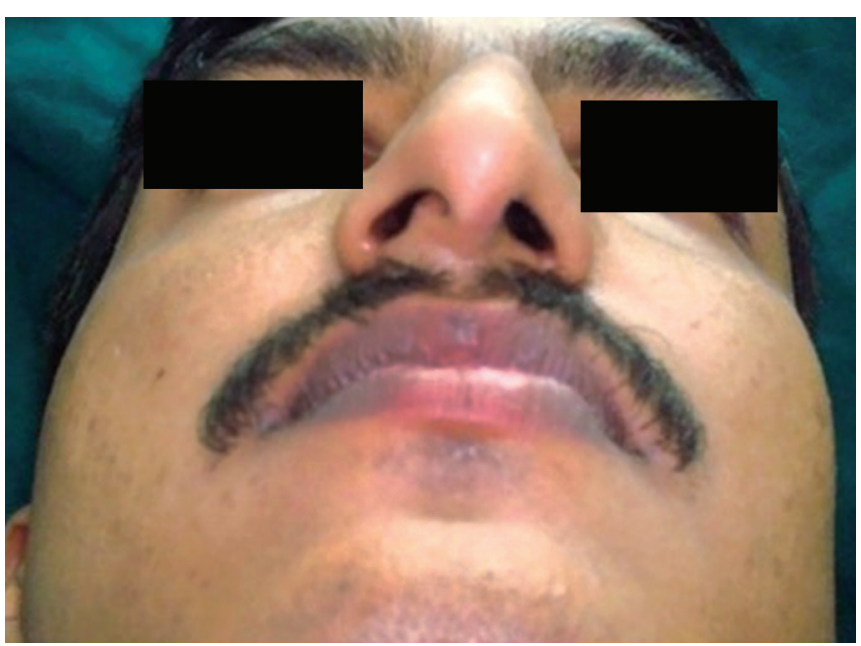

Fig. 14: Basal view before surgery

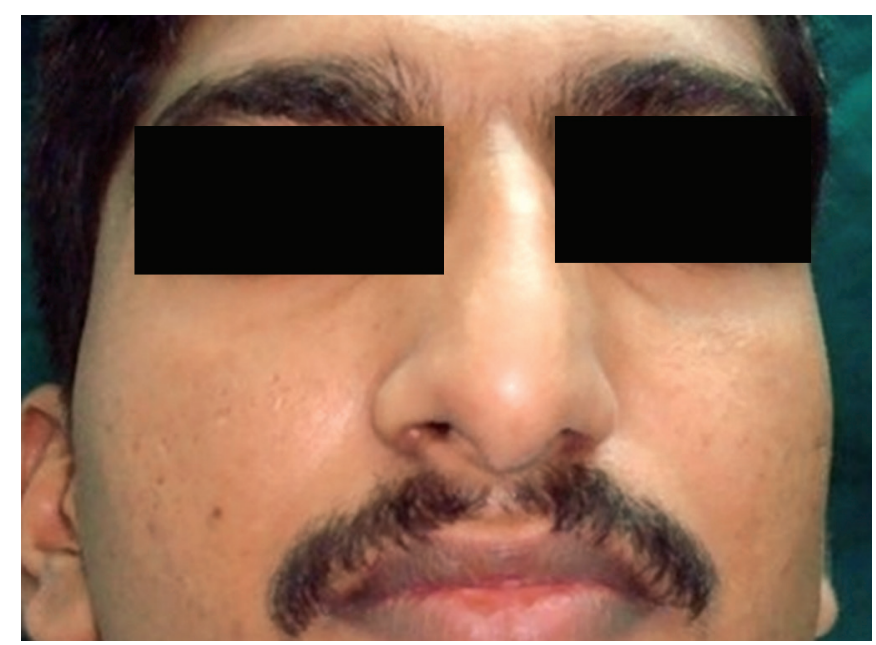

Fig. 16: Profile view before surgery

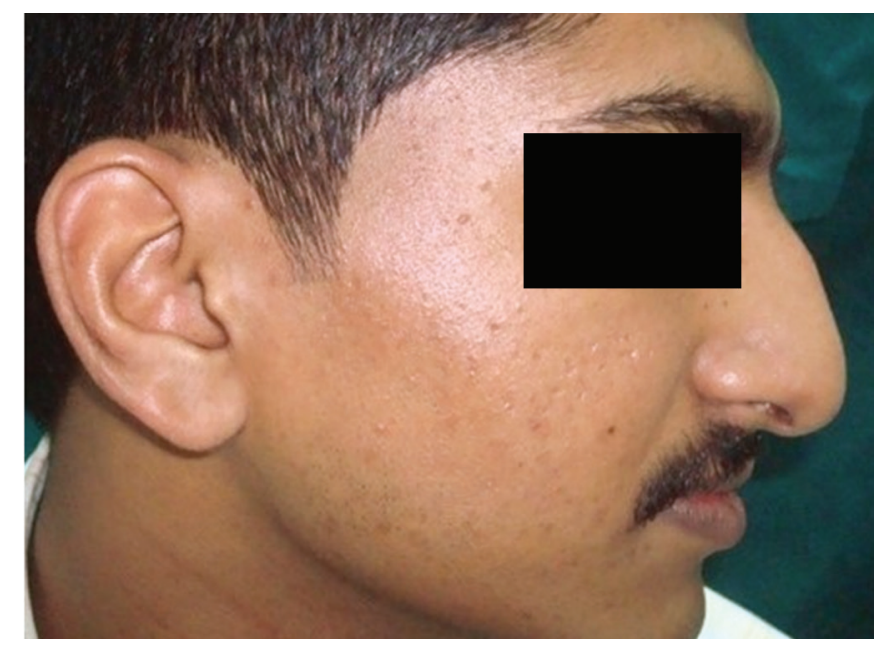

Fig. 18: Lateral view before surgery

\section{DISCUSSION}

Nasal osteotomies are controlled fractures of the nasal bones and/or adjacent maxillary processes. The nasal bones vary in thickness from person to person. The average thickness along a lateral osteotomy track was determined to be $2.47 \mathrm{~mm}$ in male patients and $2.29 \mathrm{~mm}$ in 


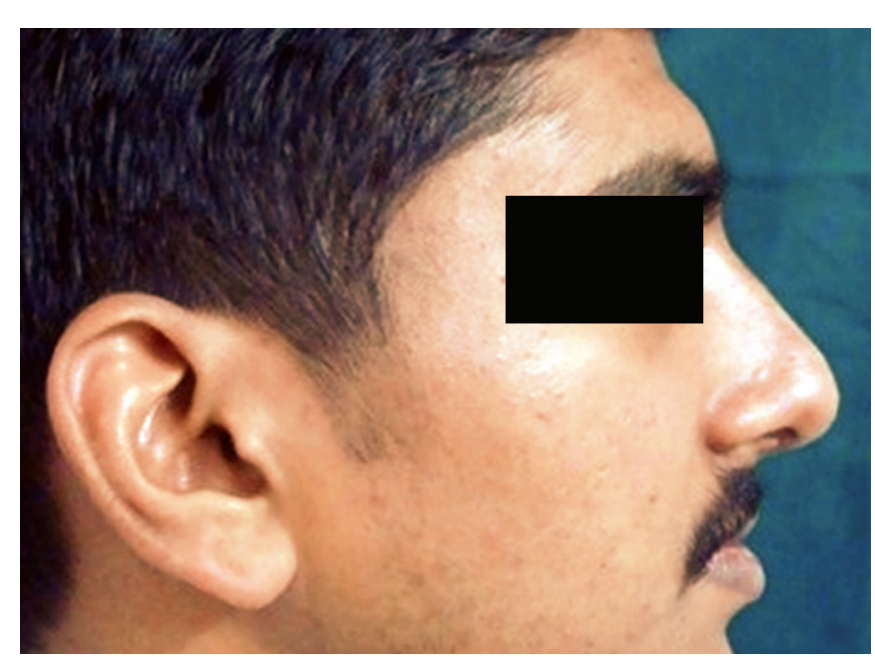

Fig. 19: Lateral view after surgery

female patients, with statistically age-related decrease in bony thickness for male patients without a corresponding observation in female patients. Citardi et $\mathrm{al}^{13}$ reviewed computerized tomography scan data and found that nasal bone thickness at the level of lateral osteotomy was $2.39 \pm 0.68($ mean $+\mathrm{SD}) \mathrm{mm}$, while nasal bone thickness at the level of intermediate osteotomy was $1.18+0.30 \mathrm{~mm}^{14}$

The nasal width should follow a graceful line from the brow to the tip, termed the brow-tip esthetic. Discrepancies in width or contour will become readily evident on frontal view. Nasal bones too widely spaced may give the impression of telecanthus. The bony width of the bony sidewall of the nose should be approximately $75 \%$ of the distance of a normal alar base on frontal view. Deviations of the nose can be more readily appreciated by drawing a straight line from the midpoint between the brows to the upper lip and central incisors, provided there are no gross facial skeletal asymmetries. If there is facial deviation present, the nose may appear "straighter" if it is in line with the rest of the facial features.

The nasal bones in shape and structure are comparable to a truncated pyramid, aka pyramidal frustum. It is inappropriate to conceptually think of osteotomies as just causing "nasal narrowing" without understanding the geometry of the nasal bones and the subsequent structural changes. A pyramidal frustum has a slant height (h), an overall height (p1), a bottom length (Lb), and top length $(\mathrm{Lt})$, and a bottom width $(\mathrm{Wb})$ and top width (Wt). Similarly, the nasal bones can be subdivided into an overall height, slant height, dorsal width (corresponding to $\mathrm{Wt}$ ), and ventral width (corresponds to $\mathrm{Wb}$ ). The dorsal width is the width created by each nasal bone as it traverses from the midline horizontally, before it curves toward the face. The ventral width is the width created by the nasal bone and the nasal process of the maxilla as it traverses down to meet the horizontal face of the maxilla. Using the pyramidal frustum as a model for nasal bone dynamics, the type and location of the osteotomy will vary according to the desired esthetic goal and underlying geometric proportions of the nasal bones.

\section{Intermediate Osteotomy}

Bony nasal framework deviation and deformities are corrected by different types of osteotomies. Medial, lateral, and transverse osteotomies must be done to move the entire bony framework as one unit. We recommend skin marking for osteotomies. It will help to fracture the bones precisely. Medial osteotomies are done as a first step of bony framework correction. If humpectomy is done, we would have created open roof deformity. Starting point of medial osteotomy will be the upper end of open roof deformity medially. Osteotomy line will be " $\mathrm{C}$ " shaped and end at the level of medial canthus.

The main indications for intermediate osteotomies ${ }^{7,8,15}$ are to narrow an extremely wide nose that has a good nasal height (bilateral osteotomies), to correct a deviated nose with one sidewall much longer than the other, and to straighten a markedly convex nasal bone. ${ }^{9}$

The intermediate osteotomy is made parallel to the lateral osteotomy along the mid-portion of the nasal sidewall and can be performed more precisely through the open rhinoplasty approach. It is performed before the lateral osteotomy, because the intermediate cut cannot be made easily after the bone is mobilized.

Routinely, we do not do intermediate osteotomies. If the lateral nasal wall is convex or concave and/or lateral nasal wall measuring more than $2.5 \mathrm{~cm}$, then there is a need for intermediate osteotomy. In this case, the left lateral wall of the nose was convex, right lateral wall of the nose was concave, and both sides the lateral wall were measuring more than $3 \mathrm{~cm}$. So, we decided to do intermediate osteotomies on the both sides.

\section{CONCLUSION}

Surgical steps must be done in an order to achieve good esthetic results. Open approach is preferred to do reduction rhinoplasty. Because, under vision, we can precisely resect hump, suture the cartilage, do the osteotomies, and do the tip plasty. Medial, intermediate, lateral, and transverse osteotomies are done as mentioned in an order to give straight and narrow dorsum. Always, do humpectomy before osteotomies and septoplasty. And, do intermediate osteotomy before lateral osteotomy. Tipplasty will be the last step of the open approach reduction rhinoplasty.

\section{REFERENCES}

1. Gunter, JP. Gunter's approach. In: Gunter, JP.; Rohrich, RJ.; Adams, WP Jr., editors. Dallas rhinoplasty: Nasal surgery by the masters. St Louis, MO: Quality Medical Publishing; 2002. p. 1049-1075. 
2. Gunter JP, Rohrich RJ. The external approach for secondary rhinoplasty. Plast Reconstr Surg 1987;80:161-173.

3. Harshbarger RJ, Sullivan PK. The optimal medial osteotomy: a study of nasal bone thickness and fracture patterns. Plast Reconstr Surg 2001 Dec;108:2114-2119.

4. Uzun L, Ugur MB, Peksoy I, Cabuk M, Cinar F. The effect of lateral osteotomy of septorhinoplasty on nasolacrimal duct functions: a radionuclide imaging study. Am J Rhinol 2005 Jul-Aug;19(4):388-394.

5. Hinton AE, Hung T, Daya H, O'Connell M. Visibility of puncture sites after external osteotomy in rhinoplastic surgery. Arch Facial Plast Surg 2003 Sep-Oct;5(5):408-411.

6. Gryskiewicz JM. Visible scars from percutaneous osteotomies. Plast Reconstr Surg 2005 Nov;116(6):1771-1775.

7. Harris MO, Baker SR. Management of the wide nasal dorsum. Arch Facial Plast Surg 2004 Jan-Feb;6(1):41-48.

8. Westreich RW, Lawson W. Perforating double lateral osteotomy. Arch Facial Plast Surg 2005 Jul-Aug;7(4):257-260.

9. Guyuron B. Nasal osteotomy and airway changes. Plast Reconstr Surg 1998 Sep;102(3):856-860; discussion 861-863.
10. Rohrich, RJ.; Hollier, LH. Rhinoplasty-dorsal reduction and spreader grafts. In Gunter, JP.; Rohrich, RJ. editors. 16th annual Dallas rhinoplasty symposium. Dallas, TX: University of Texas Southwestern Medical Center; 1999. p. 153.

11. Sheen JH. Spreader grafts: a method of reconstructing the roof of the middle nasal vault following rhinoplasty. Plast Reconstr Surg 1984 Feb;73(2):230-239.

12. Rohrich RJ. Treatment of the nasal hump with preservation of the cartilaginous framework (Discussion). Plast Reconstr Surg 1999 May;103(6):1729-1733; discussion 1734-1735.

13. Citardi MJ, Hardeman S, Hollenbeak C, Kokoska M. Computer-aided assessment of bony nasal pyramid dimensions. Arch Otolaryngol Head Neck Surg 2000 Aug;126(8): 979-984.

14. Becker DB, McLaughlin RB, Loevner LA, Mang A. The lateral osteotomy in rhinoplasty: clinical and radiographic rationale for osteotome selection. Plast Reconstr Surg 2000 Apr;105(5):1806-1816.

15. Larrabee W. Open rhinoplasty and the upper third of the nose. Facial Plast Surg Clin North Am 1993;1(1):23-38. 